Research Paper

\title{
What is the Prognostic Significance of Ki-67 Positivity in Oral Squamous Cell Carcinoma?
}

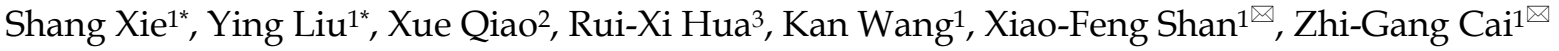 \\ 1. Department of Oral and Maxillofacial Surgery, Peking University School and Hospital of Stomatology, Beijing 100081, China; \\ 2. Department of Physiology and Pathophysiology, Peking University Health Science Center, Beijing 100191, China; \\ 3. Department of Oncology, The First Affiliated Hospital of Sun Yat-sen University, Guangzhou, Guangdong 510080, China. \\ *These authors contributed equally to this work.
}

$\triangle$ Corresponding authors: should be addressed to Zhi-Gang Cai (Department of Oral and Maxillofacial Surgery, Peking University School and Hospital of Stomatology, Beijing 100081, China. E-mail: c2013xs@163.com; Tel: +86 010 82195956, Fax: +86 010 62173402), or Xiao-Feng Shan (Department of Oral and Maxillofacial Surgery, Peking University School and Hospital of Stomatology, Beijing 100081, China. E-mail: kqsxf@263.net; Tel: +86 01082195956 , Fax: +86 010 62173402).

(1) Ivyspring International Publisher. Reproduction is permitted for personal, noncommercial use, provided that the article is in whole, unmodified, and properly cited. See http://ivyspring.com/terms for terms and conditions.

Received: 2015.10.24; Accepted: 2016.02.11; Published: 2016.04.10

\begin{abstract}
BACKGROUD: Numerous studies have stated that $\mathrm{Ki}-67$ is a good prognostic marker in oral squamous cell carcinoma (OSCC). However, some researchers believe the contrary. To address this controversy, we performed a systematic literature retrieval to estimate the prognostic significance of $\mathrm{Ki}-67$ expression in patients with OSCC. METHODS: Databases covering Pubmed, Ovid, Web of Science, Embase and the Cochrane library were searched regardless of publication year. Overall survival (OS), local recurrence (LR) and disease-free survival (DFS) were the main outcome measures. Relative risks (RRs) and its $95 \%$ confidential intervals (Cls) were used for statistical analysis. RESULTS: Twenty-seven articles with 2146 patients were included in this study. The results of the meta-analysis suggested that the pooled RRs and its Cls for OS, LR, and DFS were $1.45(1.15-1.84), 1.76(0.74-4.16)$ and $1.52(1.07-2.14)$, respectively. However, the heterogeneities of OS and LR were obvious (I-squared $(O S)=59.4 \%$, I-squared $(L R)=72.6 \%$ ). After subgroup analysis based on systemic treatment, the cut-off value of $\mathrm{Ki}-67$ expression, ethnicity and types of antibody, the heterogeneities became acceptable. It was observed that systemic treatment, cut-off values of $\mathrm{Ki}-67$ expression, ethnicity and the types of antibody affected the results. The statistical analyses of subgroups suggested that non-systemic treatment, $(\mathrm{OR}=1.77,95 \% \mathrm{Cl}=1.39-2.25, \mathrm{p}=0.000)$ and Asian populations $(\mathrm{OR}=2.09,95 \% \mathrm{Cl}=1.32-3.32$, $\mathrm{P}=0.002$ ) are high risks for $\mathrm{Ki}-67$ high expression, and low cut-off value of $\mathrm{Ki}-67$ expression (OR $=1.44,95 \% \mathrm{Cl}=1.001-2.072)$, MIB-1 antibody (OR $=1.48$, OR $95 \%=1.10-1.99)$ might affect the identification of results. CONCLUSIONS: According to this meta-analysis, high Ki-67 expression might be a negative prognostic marker of patients with OSCC, especially in Asian populations. In addition, $\mathrm{Ki}-67$ expression affects the treatment response.
\end{abstract}

Key words: Ki-67, Oral squamous cell carcinoma, OSCC, Prognosis, Survival, Meta-analysis.

\section{Introduction}

Oral cancer is one of the most common causes of cancer death in many countries. Its functional impairment and high mortality rate give rise to a heavy burden on global public health [1-3]. About ninety percent of malignant oral neoplasms are oral squamous cell carcinoma (OSCC) $[4,5]$. Despite major advances in the diagnosis and treatment of OSCC, the
5- and 10-year survival rates remains unsatisfactory $[3,6-8]$. Thus, further investigations of risk factors for tumor diagnosis and treatment are highly desirable.

Widely accepted conventional prognostic markers, such as lymph nodal status, tumor size, and cell differentiation, are not always well used in the diagnosis and prediction of OSCC $[9,10]$. Therefore, 
investigations of the tumor heterogeneity, including molecular markers, might be useful to explain the mechanism of occurrence and relapse of OSCC.

Cell proliferation is considered one of the most important mechanisms in oncogenesis [11]. In 1983, Gerdes and his colleges found that $\mathrm{Ki}-67$ is present in all proliferating cells, but absent in resting cells, which indicated that Ki-67 might be a potential tool for quick estimation of the proportion of proliferating cells in a neoplasm [12]. Subsequently, a large number of studies concerning $\mathrm{Ki}-67$ and the association between Ki-67 and tumors were reported [13-32]. Accordingly, Ki-67 was suggested as a potentially prognostic marker.

Although numerous papers reported an associated between Ki-67 and prognosis of OSCC, it has not been used in clinical practice, probably because the association remains uncertain and controversial. Thus, we decided to perform a meta-analysis to estimate and quantify the prognostic role of $\mathrm{Ki}-67$ expression comprehensively in patients with OSCC.

\section{Materials and Methods}

\section{Search Strategy}

A systematic literature search of Pubmed, Ovid, Web of Science, Embase and the Cochrane library databases was performed on Aug 182015 to identify all relevant English-language articles without publication year limitations. Four search terms "ki-67", "mouth", "neoplasms", "prognosis" were combined by the Boolean operator "and", and the search strategies were as follows: (1) marker of proliferation Ki-67 or MKI67 or Ki-67 or MIB-1 or mindbomb E3 ubiquitin protein ligase 1; and (2) mouth or oral or lip or gingiva or buccal or tongue or mouth floor or palate; and (3) neoplasm or tumor or carcinoma or cancer; and (4) prognosis or prognostic or survival. Two authors screened the retrieved papers independently. Irrelevant papers were excluded with reference to their titles and abstracts. The reference lists of all relevant papers were screened to find papers that might have been missed by the original search.

\section{Selection Criteria}

The following criteria were set and performed by three investigators (Xie, Liu and Shan): (1) the Ki-67 expression level was used to estimate the association between Ki-67 and prognosis of patients with OSCC; (2) the method of detection of Ki-67 expression was immunohistochemistry (IHC), and IHC was carried out in OSCC tumors, not normal tissues; (3) papers were written in English as a full paper; (4) odds ratio (ORs), relative risks (RRs), hazardous risks (HRs) for estimating prognosis were provided or were calculated from the original articles;

\section{Exclusion Criteria}

(1) When multiple studies from the same research group reported overlapping samples data, the study reporting the most complete dataset was included; (2) meta-analyses, reviews, conference abstracts, non-English language articles, case reports and letters were excluded; (3) lack of key information to calculate the effect size OR, RR and/or HR.

\section{Data extraction and Quality assessment}

All data were extracted independently by three authors (Xie, Liu and Shan). Differences between reviewers were resolved by consultation. The following characteristics were extracted from each included study: first author, publication data, country, no. of patients, cut-off values for estimating Ki-67 positivity, systemic treatment methods, follow-up time, clinical outcomes and other relevant information. If the authors reported OR, RR, HR and their $95 \%$ CIs, data were directly extracted from the studies. Otherwise, HR was calculated by the methods reported by Parmar et al. [33] and Tierney et al. [34] OR and RR were calculated using the incidence of events. Kaplan-Meier survival curves were read by Engauge Digitizer version 4.1. We used the Centre for Evidence Based Medicine (CEBM) criteria to evaluate the quality of all included studies $[35,36]$. The CEBM included five levels: Level 1, randomized controlled trials (RCTs) or systematic review of inception cohort studies; Level 2, low quality of RCT or inception cohort study; Level 3, cohort study; Level 4, Case-series, poor quality cohort or case-control studies; Level 5, Expert opinion without explicit critical appraisal, or bench research or "first principles". The details of its application were similar to our previous reports $[37,38]$.

\section{Statistical Analysis}

Data analyses were performed using STATA 11.0 software (Stata Co., College Station, TX, USA). The RR with its $95 \% \mathrm{CI}$ was used as the common effect size to define the association between Ki-67 expression and prognosis of patients with OSCC. The HRs were directly considered as RRs [39]. The OR was transformed into the RR using the following formula: $R R=O R /\left[\left(1-P_{0}\right)+(1-O R)\right]$, where $P_{0}$ is on behalf of the incidence of the non-exposed group outcome [40]. To estimate the heterogeneity of the included studies, the Chi-Squared test was used and significance was set at $\mathrm{p}<0.05$. The inconsistency index, I-squared, was calculated to evaluate the variation caused by heterogeneity. Where $\mathrm{p}<0.10$ and I-squared $>50 \%$, the random effect model was employed, otherwise, a 
fixed-effect model was used [41]. Funnel plots were used to detect potential publication bias, with the plots' asymmetry being estimated by Begg's test [42, 43]. Sensitivity analysis was performed to identify the underlying influence of the individual studies on the pooled RR.

\section{Results}

\section{Study Selection and Characteristics of Included Studies}

Eight hundred and one papers were retrieved by the primary search, and 458 papers remained after deleting duplicates. Among them, 349 articles were rejected as being off topic. After more detailed evaluations of the 109 potentially eligible papers, 11 were dropped as being reviews and two were deleted because they contained overlapping data. In additions, five studies were excluded as being conference abstracts or letters. A further 61 articles were excluded because of insufficient data to calculate effect size of OS, LR, or DFS. Finally, 30 articles were included in the study to evaluate the prognostic significance of Ki-67 as a molecular marker in OSCC. Among them, three articles were excluded because of their small sample size (no. of patients $<30$ ). In the remaining 27 articles $[13,22,24,25,27,28,30,32$, 44-63], 22 articles involving 23 studies concerned overall survival, six articles with seven studies concerned local recurrence, and four studies were about DFS. A flow diagram of the search is shown in Figure 1.

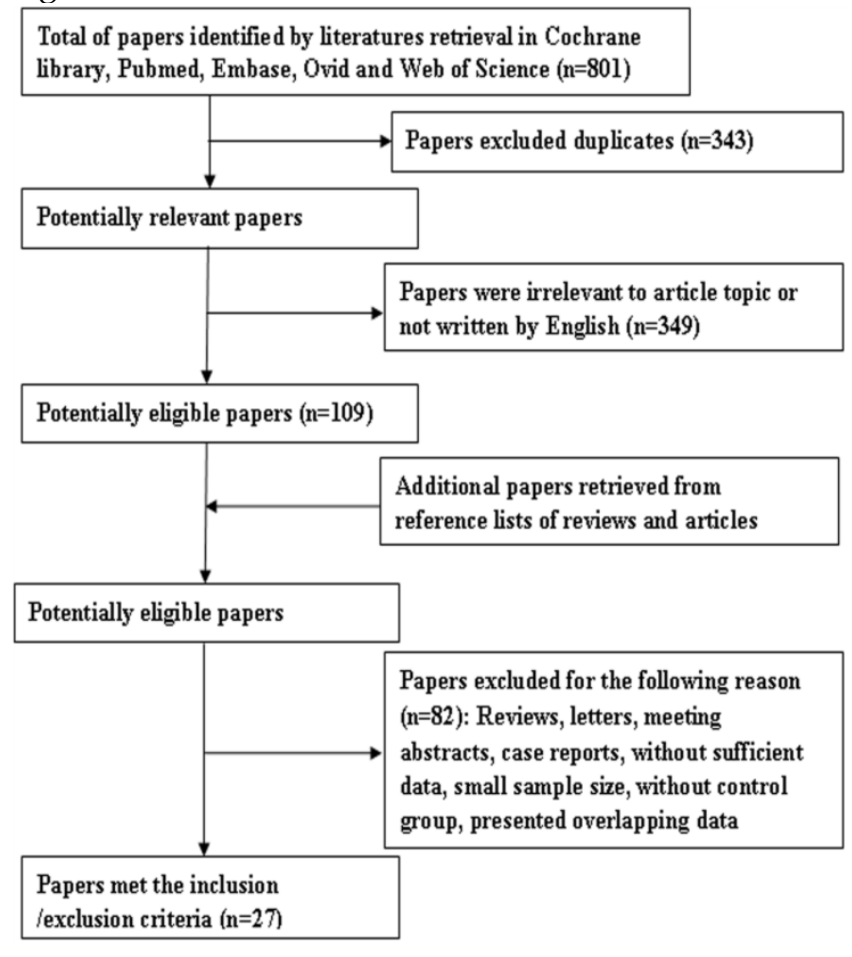

Figure 1. Flow diagram of literature retrieval.
Table 1 lists the included studies and their main features. The number of subjects included in these investigations ranged from 49 to 148, and a total of 2146 patients were involved in this meta-analysis. The follow-up period of patients ranged from 1 to 267 months; however, follow-up data for five studies were not available. The cut-off values varied from $10 \%$ to $65 \%$. Quality estimation according to CEBM showed that all these studies were level 3 (moderate quality). In addition, 13 of 27 articles were reported Ki-67 expression as a negative prognostic marker for patients with OSCC, and in the 14 remaining articles the association was not significant. Noticeable, two types of antibodies (MIB-1 and Ki-67) were used to detect antigen ki-67. Because MIB-1 can be used on formalin-fixed paraffin-embedded sections, after heat-mediated antigen retrieval, MIB-1 is more widely used than Ki-67.

\section{Impact of Ki-67 Expression on OS of Patients in OSCC}

Results of this meta-analysis suggested that worse OS was observed among OSCC patients with high Ki-67 expression ( $R R=1.45,95 \% \mathrm{CI}=1.15-1.84$, p $=0.002)$, whereas, the heterogeneity was obvious (I-squared $=59.4 \%$, PQ-test $=0.000$ ). Thus, we scrutinized all the included studies and found that the included patients came from different ethnicities and underwent the different treatment methods. Some studies only included patients that underwent systemic treatment (surgery, radiotherapy and/or chemotherapy); however, some studies enrolled patients without systemic treatment (only surgery), or partial systemic treatment. Besides, the cut-off value of Ki-67 expression and antibody types were also different among the included studies. Based on these conditions, we performed several subgroup analyses to find the underlying source of heterogeneity. Firstly, a subgroup analysis according to systemic treatment was performed. After this subgroup analysis, the heterogeneity became acceptable (systemic treatment group: I-squared $=39.2 \%$, PQ-test $=0.160$; non systemic treatment group: I-squared $=38.8 \%$, PQ-test $=0.05)$. The results revealed that systemic treatment was an important factor in improving the OS of patients with OSCC (RR=0.89, 95\% CI =0.65-1.22, $\mathrm{p}=0.461)$. We then performed subgroup analyses based on ethnicity, the cut-off value of Ki-67 expression and the types of antibodies. We found that ethnicity is also an important factor in the OS of patients with OSCC, especially in Asian populations. In addition, the cut-off value of Ki-67 expression and the types of antibodies affect the identification of prognostic significance. The details are shown in Table 2 and Figure 2. 
Table 1. Clinicopathological and Methodological Features of Eligible Studies.

\begin{tabular}{|c|c|c|c|c|c|c|c|c|c|c|c|}
\hline \multirow[t]{2}{*}{ Author } & \multirow[t]{2}{*}{ Year } & \multirow[t]{2}{*}{ Country } & \multirow{2}{*}{$\begin{array}{l}\text { No. of } \\
\text { patients }\end{array}$} & \multirow{2}{*}{$\begin{array}{l}\text { Follow-up } \\
\text { time }\end{array}$} & \multirow[t]{2}{*}{ ST } & \multirow[t]{2}{*}{ Antibody } & \multirow[t]{2}{*}{ Cut-off value } & \multicolumn{3}{|c|}{ Outcomes } & \multirow{2}{*}{$\begin{array}{l}\text { Quality } \\
\text { evaluatior }\end{array}$} \\
\hline & & & & & & & & OS & LR & DFS & \\
\hline Lange, D & 1997 & Norway & 54 & $3.6(3-12.4) y s$ & NA & MIB-1 & $37 \%$ & $1.05(0.34-3.26)$ & & & Level 3 \\
\hline Girod,S. C & 1998 & Germany & 98 & 37.6(3-96)M & NA & MIB-1 & $20 \%$ & $2.69(1.51-4.79)$ & & & Level 3 \\
\hline Bova, R. J & 1999 & Australia & 148 & 57(1-186)M & NA & Ki-67 & $50 \%$ & $1.24(0.62-2.47)$ & & $1.17(0.61-2.27)$ & Level 3 \\
\hline Xie, $X$ & 1999 & Norway & 80 & NA & NA & NA & $65 \%$ & & & $1.90(1.15-3.14)$ & Level 3 \\
\hline Couture, C & 2002 & Canada & 77 & $48(2-120) \mathrm{M}$ & Yes & MIB-1 & $20 \%$ & $0.82(0.50-1.36)$ & $0.46(0.25-0.85)$ & & Level 3 \\
\hline Myoung, $\mathrm{H}$ & 2006 & Korea & 113 & 61.0(4-87)M & NA & MIB-1 & $25 \%$ & $5.73(2.32-14.17)$ & & & Level 3 \\
\hline Szelachowska, J & 2006 & Poland & 49 & 5 ys & Yes & MIB-1 & $10 \%$ & $0.94(0.49-1.83)$ & & $0.84(0.32-2.19)$ & Level 3 \\
\hline de Aguiar,F.C.A & 2007 & Brazil & 81 & 5 years & Yes & MIB-1 & $17.50 \%$ & $1.47(0.84-2.60)$ & $0.48(0.24-0.96)$ & & Level 3 \\
\hline Kim, S. J & 2007 & $\begin{array}{l}\text { South } \\
\text { Korea }\end{array}$ & 60 & 29.5(4-117)M & NA & MIB-1 & $10 \%$ & $3.58(1.14-11.29)$ & & $2.1(0.79-5.59)$ & Level 3 \\
\hline Sakata, K. I & 2008 & Japan & 68 & 54(11-146)M & NA & MIB-1 & $38 \%$ & & $0.75(0.09-6.31)$ & & Level 3 \\
\hline Wangsa, D & 2008 & Sweden & 76 & $27(3-60) \mathrm{M}$ & NA & MIB-1 & $33 \%$ & & $3.82(0.60-24.51)$ & & Level 3 \\
\hline Faratzis, G & 2009 & Greece & 64 & 77( 16-127)M & NA & MIB-1 & $\begin{array}{l}\text { Staining intensity } \\
\text { (total score }=4 \text { ) }\end{array}$ & $2.02(1.06-3.85)$ & & & Level 3 \\
\hline Kidani, K & 2009 & Japan & 83 & $100 \mathrm{M}$ & NA & MIB-1 & $28.20 \%$ & $0.82(0.27-2.44)$ & & & Level 3 \\
\hline Lee, J. I & 2009 & Korea & 74 & NA & NA & MIB-1 & $23.50 \%$ & $1.87(0.89-3.94)$ & & & Level 3 \\
\hline Shah, N. G & 2009 & India & 89 & 16(2-39)M & NA & MIB-1 & $10 \%$ & $1.376(0.707-2.676)$ & & & Level 3 \\
\hline Wang, Z & 2009 & China & 130 & NA & Yes & Ki-67 & $15 \%$ & & $3.35(1.31-8.61)$ & & Level 3 \\
\hline $\begin{array}{l}\text { Gonzalez-Moles, } \\
\text { M. A }\end{array}$ & 2010 & Spain & 65 & $17.9(2-60) \mathrm{M}$ & Yes & MIB-1 & $25 \%$ & $0.88(0.62-1.23)$ & & & Level 3 \\
\hline Seoane, J & 2010 & Spain & 63 & $38.2 \mathrm{M}$ & NA & MIB-1 & $39 \%$ & $3.01(1.57-5.79)$ & & & Level 3 \\
\hline Watanabe, S & 2010 & Brazil & 39 & $4-96 \mathrm{M}$ & NA & Ki-67 & $22 \%$ & $0.79(0.20-3.07)$ & & & Level 3 \\
\hline Bello, I. O & 2011 & Finland & 56 & 54(1-267)M & NA & Ki-67 & $31.40 \%$ & $0.70(0.04-1.32)$ & & & Level 3 \\
\hline Freudlsperger,C(I) & 2011 & Germany & 106 & NA & NA & MIB-1 & $14.99 \%$ & $\begin{array}{l}\text { Stage I: } 2.00 \\
(0.71-5.64) ; \text { Stage II: } \\
2.02(0.36-11.36)\end{array}$ & $1.34(0.80-2.24)$ & & Level 3 \\
\hline Bitu, C. C & 2012 & Brazil & 127 & 5 years & NA & Ki-67 & $23 \%$ & $1.21(0.78-1.75)$ & & & Level 3 \\
\hline $\begin{array}{l}\text { Freudlsperger,C } \\
\text { (II) }\end{array}$ & 2012 & Germany & 52 & NA & Yes & MIB-1 & $20.53 \%$ & $0.39(0.16-0.92)$ & $0.30(0.09-0.97)$ & & Level 3 \\
\hline Avirovic, $\mathrm{M}$ & 2013 & Croatia & 85 & 5 years & NA & MIB-1 & $20 \%$ & $1.231(0.69-2.18)$ & & & Level 3 \\
\hline Wei, Z-C & 2013 & China & 64 & 43.2(2-101)M & NA & Ki-67 & $\begin{array}{l}\text { Staining intensity } \\
\text { (total score }=4 \text { ) }\end{array}$ & $1.26(0.52-3.07)$ & & & Level 3 \\
\hline Gontarz, M & 2014 & Poland & 60 & $>5$ years & NA & MIB-1 & $25 \%$ & & $\begin{array}{l}\text { S: } 5.42 \\
(1.18-24.83) ; \\
\text { S+RT: } \\
0.97(0.39-2.40)\end{array}$ & & Level 3 \\
\hline Toyoda,M & 2014 & Japan & 85 & $34.4(2-115) \mathrm{M}$ & NA & Ki-67 & $21 \%$ & $3.12(1.59-6.11)$ & & & Level 3 \\
\hline
\end{tabular}

ST: systemic treatment; NA: not available; OS: overall survival; LR: local recurrence; DFS: disease-free survival; S: surgery; RT: radiotherapy.

Table 2. Meta-analyses Estimating the Associtaions Between Ki-67 and Clinical Outcomes of OSCC

\begin{tabular}{|c|c|c|c|c|c|c|c|}
\hline \multirow[t]{2}{*}{ Clinicopathological variables } & \multirow[t]{2}{*}{ No. of studies } & \multirow[t]{2}{*}{ Cases } & \multicolumn{2}{|l|}{ Pooled data } & \multicolumn{3}{|c|}{ Test for heterogeneity } \\
\hline & & & OR $(95 \% \mathrm{CI})$ & $\mathrm{P}$ & $\mathrm{Chi}^{2}$ & $\mathrm{p}$ & $\mathrm{I}^{2}$ \\
\hline \multicolumn{8}{|l|}{ Overall survival } \\
\hline All studies & 23 & 1732 & $1.45(1.15-1.84)$ & 0.002 & 54.19 & 0.00 & $59.4 \%$ \\
\hline \multicolumn{8}{|c|}{ Subgroup analysis by treatment methods } \\
\hline ST & 5 & 324 & $0.89(0.65-1.22)$ & 0.461 & 6.58 & 0.16 & $39.2 \%$ \\
\hline ST(NA) & 18 & 1408 & $1.77(1.39-2.25)$ & 0.000 & 27.60 & 0.05 & $38.4 \%$ \\
\hline \multicolumn{8}{|c|}{ Subgroup analysis by cut-off value } \\
\hline$\leq 21 \%$ & 11 & 782 & $1.44(1.001-2.07)$ & 0.049 & 27.79 & 0.002 & $64.0 \%$ \\
\hline$>21 \%$ & 10 & 822 & $1.43(0.97-2.11)$ & 0.068 & 24.5 & 0.004 & $63.3 \%$ \\
\hline \multicolumn{8}{|l|}{ Subgroup analysis by antibody } \\
\hline MIB-1 & 17 & 1213 & $1.48(1.10-1.99)$ & 0.009 & 46.75 & 0.000 & $65.8 \%$ \\
\hline Ki-67 & 6 & 519 & $1.41(0.96-2.07)$ & 0.084 & 7.40 & 0.193 & $32.4 \%$ \\
\hline \multicolumn{8}{|l|}{ Subgroup analysis by ethnicity } \\
\hline Asian & 7 & 568 & 2.09(1.32-3.32) & 0.002 & 12.59 & 0.05 & $52.3 \%$ \\
\hline Caucasian & 12 & 769 & $1.27(0.90-1.80)$ & 0.173 & 31.60 & 0.001 & $65.2 \%$ \\
\hline Mixed & 4 & 395 & $1.26(0.94-1.68)$ & 0.125 & 0.77 & 0.855 & $0.0 \%$ \\
\hline \multicolumn{8}{|l|}{ Local recurrence } \\
\hline All studies & 7 & 457 & $1.76(0.74-4.16)$ & 0.198 & 21.86 & 0.001 & $72.6 \%$ \\
\hline \multicolumn{8}{|l|}{ Subgroup } \\
\hline ST & 3 & 233 & $1.10(0.35-3.48)$ & 0.874 & 12.08 & 0.002 & $83.4 \%$ \\
\hline ST(NA) & 4 & 224 & $3.35(1.40-8.03)$ & 0.007 & 2.39 & 0.496 & $0.0 \%$ \\
\hline Disease-free survival & 4 & 337 & $1.51(1.07-2.14)$ & 0.018 & 3.25 & 0.355 & $7.6 \%$ \\
\hline
\end{tabular}

ST: systemic treatment; NA: not available or no systemic treatment. 
A $\quad$ Stud

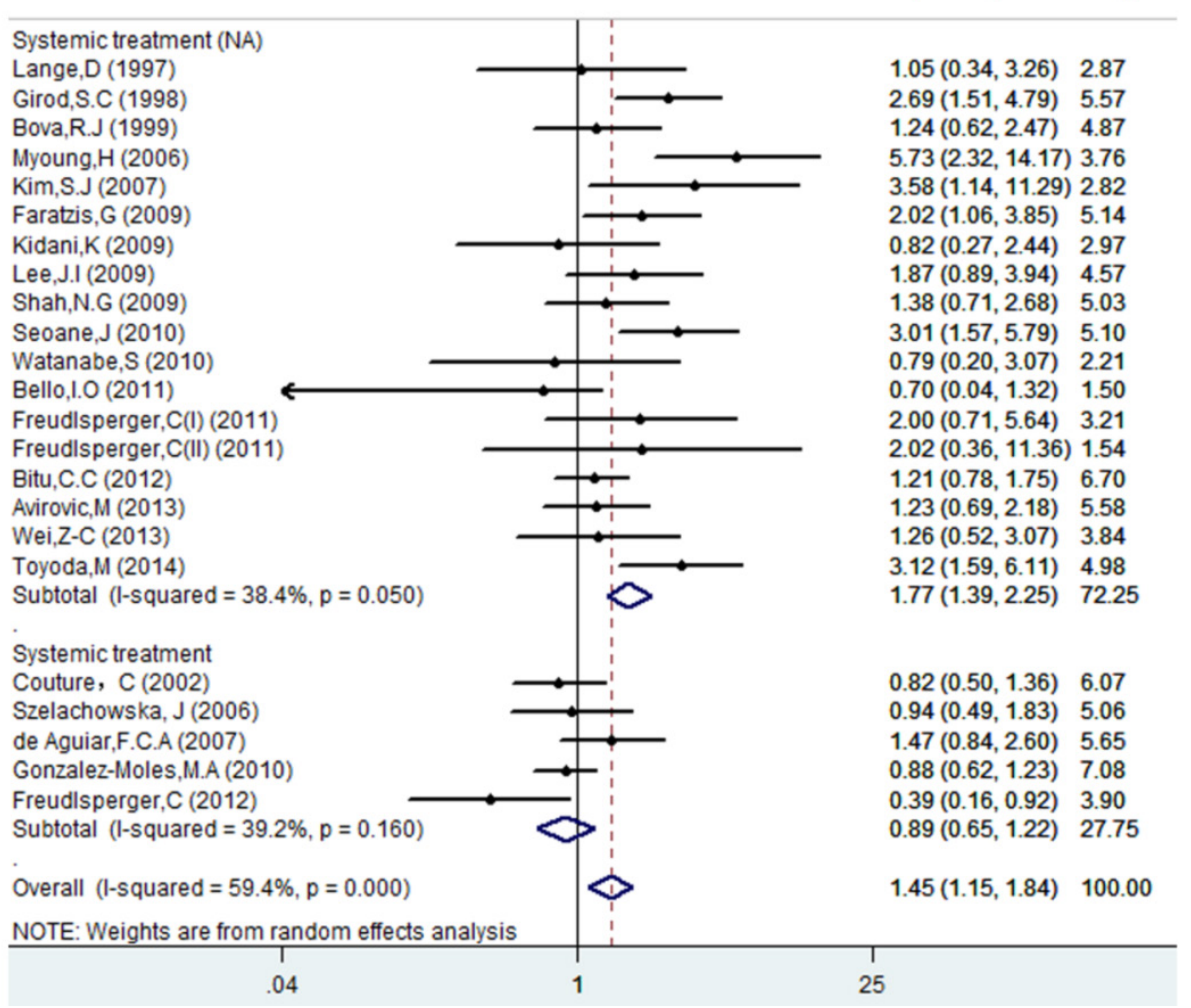

B Study

RR $(95 \% \mathrm{Cl}) \quad$ Weight

Caucasian

Lange,D (1997)

Girod,S.C (1998)

Couture, C (2002)

Szelachowska, J (2006)

Faratzis, G (2009)

Gonzalez-Moles,M.A (2010)

Seoane,J (2010)

Bello,I.O (2011)

Freudlsperger,C(I) (2011)

Freudlsperger,C(II) (2011)

Freudlsperger,C (2012)

Avirovic,M (2013)

Subtotal (l-squared $=65.2 \%, p=0.001$ )

Mixed

Bova, R.J (1999)

de Aguiar,F.C.A (2007)

Watanabe,S (2010)

Bitu,C.C (2012)

Subtotal (l-squared $=0.0 \%, p=0.855)$

Asian

Myoung. $\mathrm{H}(2006)$

Kim,S.J (2007)

Kidani,K (2009)

Lee.J.I (2009)

Shah.N.G (2009)

Wei,Z-C (2013)

Toyoda,M (2014)

Subtotal (l-squared $=52.3 \%, p=0.050$ )

Overall (1-squared $=59.4 \%, p=0.000$ )

NOTE: Weights are from random effects analysis

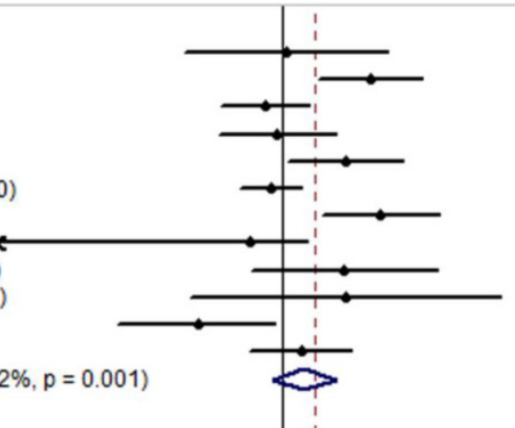

$1.05(0.34,3.26) 2.87$

$2.69(1.51,4.79) 5.57$

$0.82(0.50,1.36) 6.07$

$0.94(0.49,1.83) 5.06$

$2.02(1.06,3.85) 5.14$

$0.88(0.62,1.23) 7.08$

$3.01(1.57,5.79) 5.10$

$0.70(0.04,1.32) 1.50$

$2.00(0.71,5.64) 3.21$

$2.02(0.36,11.36) 1.54$

$0.39(0.16,0.92) 3.90$

$1.23(0.69,2.18) 5.58$

$1.27(0.90,1.80) 52.62$

$1.24(0.62,2.47) 4.87$

$1.47(0.84,2.60) 5.65$

$0.79(0.20,3.07) 2.21$

$1.21(0.78,1.75) 6.70$

$1.25(0.94,1.68) 19.42$

$5.73(2.32,14.17) 3.76$

$3.58(1.14,11.29) 2.82$

$0.82(0.27,2.44) 2.97$

$1.87(0.89,3.94) 4.57$

$1.38(0.71,2.68) 5.03$

$1.26(0.52,3.07) 3.84$

$3.12(1.59,6.11) 4.98$

$2.09(1.32,3.32) 27.96$

$1.45(1.15,1.84) 100.00$ 
C $\quad$ Study

Cut-off value $\leq 21 \%$

Szelachowska, J (2006)

Kim,S.J (2007)

Shah,N.G (2009)

Freudlsperger, $C(I)$ (2011)

Freudlsperger,C(II) (2011)

de Aguiar,F.C.A (2007)

Girod,S.C (1998)

Couture, C (2002)

Avirovic,M (2013)

Freudlsperger,C (2012)

Toyoda,M (2014)

Subtotal $(I-$ squared $=64.0 \%, p=0.002)$

Cut-off value $>21 \%$

Watanabe, S (2010)

Bitu,C.C (2012)

Lee,J.I (2009)

Myoung, $\mathrm{H}$ (2006)

Gonzalez-Moles,M.A (2010)

Kidani,K (2009)

Bello,I.O (2011)

Lange, D (1997)

Seoane,J (2010)

Bova,R.J (1999)

Subtotal (l-squared $=63.3 \%, p=0.004$ )

Overall (I-squared $=62.0 \%, p=0.000$ )

NOTE: Weights are from random effects analysis

.04

Study

ID

MIB-1

Lange,D (1997)

Girod,S.C (1998)

Couture, C (2002)

Myoung,H (2006)

Szelachowska, J (2006)

de Aguiar,F.C.A (2007)

Kim,S.J (2007)

Faratzis, G (2009)

Kidani,K (2009)

Lee,J.I (2009)

Shah, N.G (2009)

Gonzalez-Moles,M.A (2010)

Seoane,J (2010)

Freudlsperger,C(I) (2011)

Freudlsperger,C(II) (2011)

Freudlsperger,C (2012)

Avirovic, M (2013)

Subtotal $(1-$ squared $=65.8 \%, p=0.000)$

Ki-67

Bova,R.J (1999)

Watanabe, S (2010)

Bello,I.O (2011)

Bitu, C.C (2012)

Wei,Z-C (2013)

Toyoda,M (2014)

Subtotal $(\mathrm{l}$-squared $=32.4 \%, p=0.193)$

Overall (l-squared $=59.4 \%, p=0.000$ )

NOTE: Weights are from random effects analysis

$$
04
$$

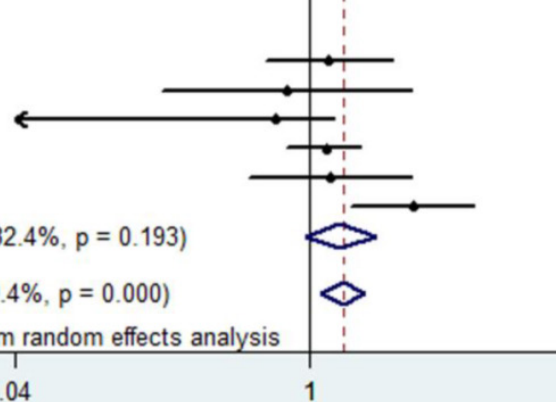

1
$\%$

RR $(95 \% \mathrm{Cl}) \quad$ Weight

$0.94(0.49,1.83) 5.55$

$3.58(1.14,11.29) 3.17$

$1.38(0.71,2.68) 5.52$

$2.00(0.71,5.64) 3.60$

$2.02(0.36,11.36) 1.76$

$1.47(0.84,2.60) 6.15$

$2.69(1.51,4.79) 6.07$

$0.82(0.50,1.36) 6.57$

$1.23(0.69,2.18) 6.08$

$0.39(0.16,0.92) 4.33$

$3.12(1.59,6.11) 5.46$

$1.44(1.00,2.07) 54.25$

$0.79(0.20,3.07) 2.50$

$1.21(0.78,1.75) 7.21$

$1.87(0.89,3.94) 5.04$

$5.73(2.32,14.17) 4.18$

$0.88(0.62,1.23) 7.59$

$0.82(0.27,2.44) 3.34$

$0.70(0.04,1.32) 1.72$

$1.05(0.34,3.26) 3.23$

$3.01(1.57,5.79) 5.59$

$1.24(0.62,2.47) 5.35$

$1.43(0.97,2.11) 45.75$

$1.44(1.11,1.85) 100.00$

25

$\%$ Weight

(1.05 (0.34, 3.26) 2.87

$1.05(0.34,3.26) 2.87$

$2.69(1.51,4.79) 5.57$

$0.82(0.50,1.36) 6.07$

$5.73(2.32,14.17) 3.76$

$0.94(0.49,1.83) 5.06$

$1.47(0.84,2.60) 5.65$

$3.58(1.14,11.29) 2.82$

$2.02(1.06,3.85) 5.14$

$0.82(0.27,2.44) 2.97$

$1.87(0.89,3.94) 4.57$

$1.38(0.71,2.68) 5.03$

$0.88(0.62,1.23) 7.08$

$3.01(1.57,5.79) 5.10$

$2.00(0.71,5.64) 3.21$

$2.02(0.36,11.36) 1.54$

$0.39(0.16,0.92) 3.90$

$1.23(0.69,2.18) 5.58$

$1.48(1.10,1.99) 75.91$

$1.24(0.62,2.47) 4.87$

$0.79(0.20,3.07) 2.21$

$0.70(0.04,1.32) 1.50$

$1.21(0.78,1.75) 6.70$

$1.26(0.52,3.07) 3.84$

$3.12(1.59,6.11) 4.98$

$1.41(0.96,2.07) 24.09$

$1.45(1.15,1.84) 100.00$

25

Figure 2. Forest plot evaluating the impact of Ki-67 expression on overall survival of patients with OSCC.A: Based on the subgroup of systemic treatment; B: Based on the subgroup of ethnicity; C: Based on the subgroup of cut-off value; D: Based on the subgroup of the types of antibodies. 


\section{Impact of Ki-67 Expression on LR of Patients in OSCC}

The results of this meta-analysis suggested that there was significant heterogeneity among these included articles (I-squared $=72.6 \%, \mathrm{P}_{\mathrm{Q} \text {-test }}=0.001$ ), and a random-effect model with subgroup analysis based on systemic treatment was performed to combine the RRs and their 95\% CIs. The subgroup analysis also demonstrated that those patients who received systemic treatment $(R R=1.10,95 \%=0.35-3.48, p=0.874)$ had less risk than those without systemic treatment $(R R=3.35,95 \%=1.40-8.03, p=0.007)$. The sample size for LR was very small; therefore, other subgroups analyses were not performed to avoid overinterpretation. The details are shown in Table 2 and Figure 3.

\section{Impact of Ki-67 Expression on DFS of Patients in OSCC}

The results of this meta-analysis showed no obvious heterogeneity among the included articles (I-squared $=7.6 \%, P_{Q-t e s t}=0.355$ ), and a fixed-effect model was performed to combine the RRs and their $95 \%$ CIs $(R R=1.52,95 \% \mathrm{CI}=1.07-2.04, \mathrm{p}=0.018)$. The results showed that $\mathrm{Ki}-67$ positivity plays a significantly negative role on the DFS of patients (Table 2, Figure 4).

\section{Publication Bias and Sensitivity Analysis}

Potential publication bias and sensitivity were evaluated using Begg's funnel plots and sensitivity analysis. Begg's test demonstrated that no significant publication bias existed in this study, and the values of Begg's test for OS, LR and DFS were 0.635, 1.000 and 0.734, respectively (Figure 5). The sensitivity analysis gave rise to variation only between the lower and upper CI limits, suggesting that our study results are robust and credible (Data not shown).

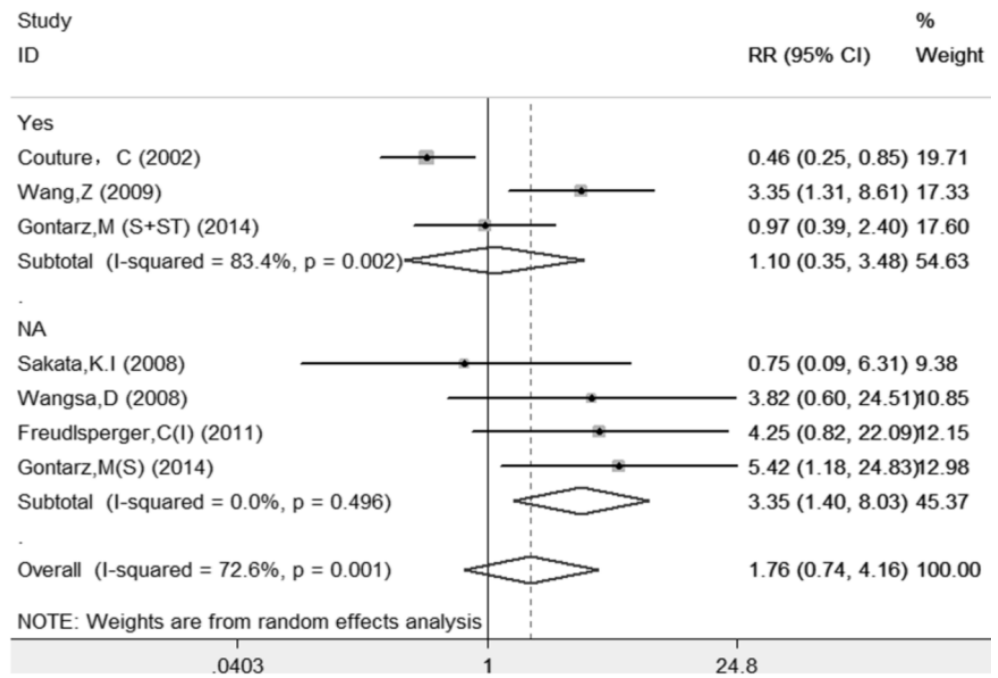

Figure 3. Forest plot evaluating the impact of $\mathrm{Ki}-67$ expression on local recurrence of patients with OSCC (based on the subgroup of systemic treatment).
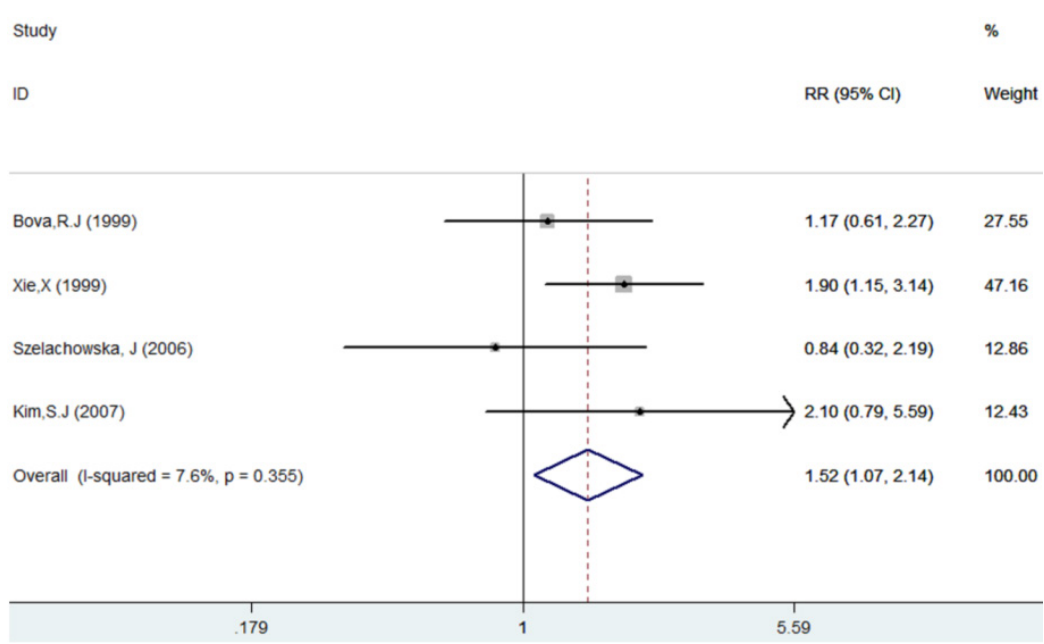

Figure 4. Forest plot evaluating the impact of Ki-67 expression on disease-free survival of patients with OSCC. 


\section{Discussion}

The Ki-67 gene is located on human chromosome 10 (10q25) [64]. In 1993, Schluter and his colleagues reported the complete cDNA sequence encoding the protein [65]. The location and cellular appearance of $\mathrm{Ki}-67$ is dynamic throughout a cell's life [66, 67]. Ki-67 expression is low during G1- and early S-phase, but progressively increases to reach a maximum during mitosis $[66,67]$. This indicated that Ki-67 might be applied as a marker for different conditions of cell growth. Cell proliferation is closely related to tumor
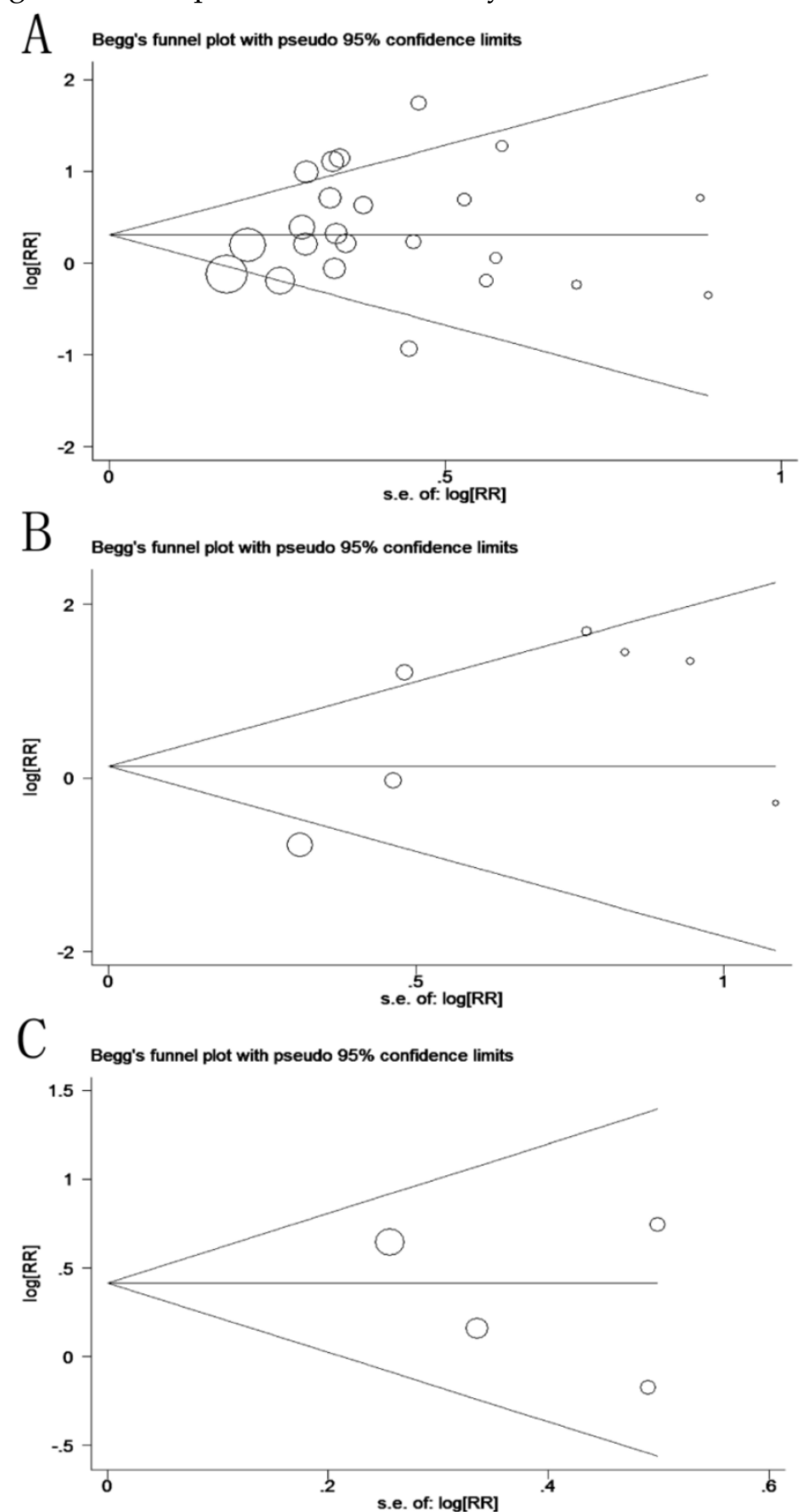

Figure 5. Funnel plot for prognosis of patients with OSCC (A: overall survival, $p$ (Begg's test $)=0.635$; B: local recurrence, $p($ Begg's test $)=1.000$; C: disease-free survival, $p($ Begg's test $)=0.734$ ) recurrence. Thus, Ki-67 might be regarded as a potential molecular indicator in the prognosis of a tumor.

Many studies have demonstrated the relevance of $\mathrm{Ki}-67$ to the prognosis of cancers, such as breast cancer, lung cancer and prostate cancer [68-71]. Although the role of $\mathrm{Ki}-67$ in patients with OSCC has been debatable for two decades [24, 32, 61, 72, 73], no study has solved the contradiction convincingly. To explore the contradictory results, we searched published papers and found that more than one hundred articles were involved in this topic. Among these papers, supporters [25, 49, 52] declared that $\mathrm{Ki}-67$ expression is related to the cell proliferative index, which is consistent with tumor progression and recurrence, and dissenters $[24,32,44]$ claimed that the proliferative index is unequal to the rate of proliferation. Besides, some authors [13, 30] asserted that Ki-67 expression predicts radiosensitivity in OSCC. However, most of the conclusions were based on small sample sizes and different intervention methods, which might be the source of the controversy. Thus, we carried out a meta-analysis to further estimate and quantify the clinical significance of $\mathrm{Ki}-67$ in patients with OSCC.

In this meta-analysis, the results demonstrated that high Ki-67 expression in patients with OSCC results in worse prognosis among patients overall. However, systemic treatment could improve prognosis of patients with high Ki-67 expression. Subgroup analysis of systemic treatment not only decreased the heterogeneities but also confirmed that systemic treatment was an important method to improve the prognosis of patients considered as positive patients, which meant that patients with high Ki-67 expression should be treated systemically. Another subgroup analysis based on ethnicity demonstrated that ethnicity might also affect the prognosis of OSCC patients. The high expression of $\mathrm{Ki}-67$ in Asian populations is also a high risk factor. Besides, the subgroup analyses according to the types of antibodies and the cut-off value suggested that different antibodies and cut-off values might affect the identification of a prognostic role of $\mathrm{Ki}-67$ expression. To estimate the reliability of the results, we performed sensitivity analyses as well as evaluation of publication bias in our study. According to quality evaluation of included studies, our results were supported at level 3 (moderate quality), which could be considered as traditionally trusted. All the results suggested that the results from out meta-analysis are stable and reliable. 
However, there are still several limitations in this meta-analysis study. First, the use of different antibodies and methods might account for some of the conflicts. In this study, most of the authors assessed Ki-67 expression by the percentage of cells that stained positively for the Ki-67 antigen; however, several researchers estimated Ki-67 expression by the levels of staining intensity. Unfortunately, limited information blocked further exploration. Second, the evaluated HR might be less reliable than those gained from published data. Both the methods of extraction of $\mathrm{HR}$ and conversion of OR to RR might produce potential bias. Third, the follow-up time varied from 1 to 267 months, which might reduce the credibility of results. Fourth, the sample size of this meta-analysis remained small, especially the sample size for LR and DFS. Thus, the results should be interpreted with caution.

Despite several disadvantages, by quantifying the original data from the included studies, our meta-analysis reaches the conclusion that $\mathrm{Ki}-67$ expression is a poor prognostic marker for patients with OSCC and could promote the response of systemic treatment. If possible, multiparameter studies with the large sample sizes and standard IHC techniques are recommended for further investigations.

\section{Acknowledgements}

This work was supported by grants from the National Natural Science Foundation of China (NSFC-81371162, 81100762 and 30973336). The sponsors had no role in study design, data collection and analysis, the preparation of the manuscript, decision to publish, or submit the manuscript for publication.

\section{Conflict of Interest}

The authors declare no conflicts of interest.

\section{References}

1. Kademani D. Oral cancer. Mayo Clinic proceedings. 2007; 82: 878-87.

2. Siegel R, Ma J, Zou Z, Jemal A. Cancer statistics, 2014. CA: a cancer journal for clinicians. 2014; 64: 9-29.

3. Siegel RL, Miller KD, Jemal A. Cancer statistics, 2015. CA: a cancer journal for clinicians. 2015; 65: 5-29.

4. Bray F, Sankila R, Ferlay J, Parkin DM. Estimates of cancer incidence and mortality in Europe in 1995. European journal of cancer (Oxford, England : 1990). 2002; 38: 99-166.

5. Parkin DM, Bray F, Ferlay J, Pisani P. Global cancer statistics, 2002. CA: a cancer journal for clinicians. 2005; 55: 74-108.

6. Chen GS, Chen $\mathrm{CH}$. A study on survival rates of oral squamous cell carcinoma. The Kaohsiung journal of medical sciences. 1996; 12: 317-25.

7. Goldenberg D, Mackley H, Koch W, Bann DV, Schaefer EW, Hollenbeak CS. Age and stage as determinants of treatment for oral cavity and oropharyngeal cancers in the elderly. Oral oncology. 2014; 50: 976-82.

8. Bettendorf O, Piffko J, Bankfalvi A. Prognostic and predictive factors in oral squamous cell cancer: important tools for planning individual therapy? Oral oncology. 2004; 40: 110-9.

9. Woolgar JA. Pathology of the N0 neck. The British journal of oral \& maxillofacial surgery. 1999; 37: 205-9.
10. Bryne M, Koppang HS, Lilleng R, Kjaerheim A. Malignancy grading of the deep invasive margins of oral squamous cell carcinomas has high prognostic value. The Journal of pathology. 1992; 166: 375-81.

11. van Diest PJ, Brugal G, Baak JP. Proliferation markers in tumours: interpretation and clinical value. Journal of clinical pathology. 1998; 51: 716-24.

12. Gerdes J, Schwab U, Lemke H, Stein H. Production of a mouse monoclonal antibody reactive with a human nuclear antigen associated with cell proliferation. International journal of cancer Journal international du cancer. 1983; 31: 13-20.

13. Couture C, Raybaud-Diogene H, Tetu B, Bairati I, Murry D, Allard J, et al. p53 and $\mathrm{Ki}-67$ as markers of radioresistance in head and neck carcinoma. Cancer. 2002; 94: 713-22.

14. Igarashi N, Takahashi M, Ohkubo H, Omata K, Iida R, Fujimoto S. Predictive value of Ki-67, p53 protein, and DNA content in the diagnosis of gastric carcinoma. Cancer. 1999; 86: 1449-54.

15. Iwata H, Masuda N, Sagara Y, Kinoshita T, Nakamura S, Yanagita Y, et al. Analysis of Ki-67 expression with neoadjuvant anastrozole or tamoxifen in patients receiving goserelin for premenopausal breast cancer. Cancer. 2013; 119: 704-13.

16. Shiba M, Kohno H, Kakizawa K, Iizasa T, Otsuji M, Saitoh Y, et al. Ki-67 immunostaining and other prognostic factors including tobacco smoking in patients with resected nonsmall cell lung carcinoma. Cancer. 2000; 89: 1457-65.

17. Stapleton AM, Zbell P, Kattan MW, Yang G, Wheeler TM, Scardino PT, et al. Assessment of the biologic markers p53, Ki-67, and apoptotic index as predictive indicators of prostate carcinoma recurrence after surgery. Cancer. 1998; 82: 168-75

18. Sittel C, Ruiz S, Volling P, Kvasnicka HM, Jungehulsing M, Eckel HE. Prognostic significance of Ki-67 (MIB1), PCNA and p53 in cancer of the oropharynx and oral cavity. Oral oncology. 1999; 35: 583-9.

19. Matos F, Brandao L, Dias F, Lima R, Vasconcellos S, Santiago T, et al. Expression of Ki-67 and endoglin (CD 105) proteins in stages I and II squamous cell carcinoma of oral tongue and floor of the mouth: association with demographic, clinical and histopathological factors - prognostic analysis. Oral oncology. 2007: 174.

20. Xie X, De Angelis P, Clausen OPF, Boysen M. Prognostic significance of proliferative and apoptotic markers in oral tongue squamous cell carcinomas. Oral oncology. 1999; 35: 502-9.

21. Silva SD, Perez DE, Alves FA, Nishimoto IN, Pinto CAL, Kowalski LP, et al. ErbB2 and fatty acid synthase (FAS) expression in 102 squamous cell carcinomas of the tongue: Correlation with clinical outcomes. Oral oncology. 2008; 44: 484-90.

22. Kidani K, Osaki M, Tamura T, Yamaga K, Shomori K, Ryoke K, et al. High expression of EZH2 is associated with tumor proliferation and prognosis in human oral squamous cell carcinomas. Oral oncology. 2009; 45: 39-46.

23. Chen F, Zhang J, Wang L, Wang $\mathrm{Y}$, Chen M. Tumor $\mathrm{pH}(\mathrm{e})$-triggered charge-reversal and redox-responsive nanoparticles for docetaxel delivery in hepatocellular carcinoma treatment. Nanoscale. 2015; 7: 15763-79.

24. Gonzalez-Moles MA, Ruiz-Avila I, Gil-Montoya JA, Esteban F, Bravo M. Analysis of Ki-67 expression in oral squamous cell carcinoma: Why Ki-67 is not a prognostic indicator. Oral oncology. 2010; 46: 525-30.

25. Faratzis G, Tsiambas E, Rapidis AD, Machaira A, Xiromeritis K, Patsouris E. VEGF and ki 67 expression in squamous cell carcinoma of the tongue: An immunohistochemical and computerized image analysis study. Oral oncology. 2009; 45: 584-8.

26. de Vicente JC, Herrero-Zapatero A, Fresno MF, Lopez-Arranz JS. Expression of cyclin D1 and Ki-67 in squamous cell carcinoma of the oral cavity: clinicopathological and prognostic significance. Oral oncology. 2002; 38: 301-8.

27. de Aguiar FCA, Kowalski LP, de Almeida SP. Clinicopathological and immunohistochemical evaluation of oral squamous cell carcinoma in patients with early local recurrence. Oral oncology. 2007; 43: 593-601.

28. Bello IO, Vered M, Dayan D, Dobriyan A, Yahalom R, Alanen K, et al. Cancer-associated fibroblasts, a parameter of the tumor microenvironment, overcomes carcinoma-associated parameters in the prognosis of patients with mobile tongue cancer. Oral oncology. 2011; 47: 33-8.

29. Baek KW, Han KD, Yun PY, Myoung H, Lee JH, Kim MJ. Correlation of proliferative markers (Ki-67 and PCNA) with survival and lymph node metastasis in oral squamous cell carcinoma: a clinical and histopathological analysis of 113 patients. Oral oncology. 2007: 157-.

30. Freudlsperger C, Freier K, Hoffmann J, Engel M. Ki-67 expression predicts radiosensitivity in oral squamous cell carcinoma. International journal of oral and maxillofacial surgery. 2012; 41: 965-9.

31. Coutinho-Camillo CM, Lourenco SV, Nishimoto IN, Kowalski LP, Soares FA. Nucleophosmin, p53, and Ki-67 expression patterns on an oral squamous cell carcinoma tissue microarray. Human pathology. 2010; 41: 1079-86.

32. Wangsa D, Ryott M, Avall-Lundqvist E, Petersson F, Elmberger G, Luo J, et al. $\mathrm{Ki}-67$ expression predicts locoregional recurrence in stage I oral tongue carcinoma. British journal of cancer. 2008; 99: 1121-8.

33. Parmar MK, Torri V, Stewart L. Extracting summary statistics to perform meta-analyses of the published literature for survival endpoints. Statistics in medicine. 1998; 17: 2815-34

34. Tierney JF, Stewart LA, Ghersi D, Burdett S, Sydes MR. Practical methods for incorporating summary time-to-event data into meta-analysis. Trials. 2007; 8: 16

35. [Internet] Jeremy Howick, Iain Chalmers, Paul Glasziou, Trish Greenhalgh, Carl Heneghan, Alessandro Liberati, et al. Oxford Centre for Evidence-based 
Medicine - Levels of Evidence. http://www.cebm.net/oxford-centreevidence-based-medicine-levels-evidence-march-2009/; 2009.

36. [Internet] Jeremy Howick, Iain Chalmers, Paul Glasziou, Trish Greenhalgh, Carl Heneghan, Alessandro Liberati, et al. The Oxford Levels of Evidence 2. Oxford Centre for Evidence-Based Medicine. http://www.cebm.net/oxfordcentre-evidence-based-medicine-levels-evidence-march-2009/; 2011.

37. Xie S, Wang K, Xu T, Guo XS, Shan XF, Cai ZG. Efficacy and safety of botulinum toxin type A for treatment of Frey's syndrome: evidence from 22 published articles. Cancer medicine. 2015: [Epub ahead of print].

38. Xie S, Wang K, Xu H, Hua RX, Li TZ, Shan XF, et al. PRISMA-Extracapsular Dissection Versus Superficial Parotidectomy in Treatment of Benign Parotid Tumors: Evidence From 3194 Patients. Medicine. 2015; 94: e1237.

39. Willi C, Bodenmann P, Ghali WA, Faris PD, Cornuz J. Active smoking and the risk of type 2 diabetes: a systematic review and meta-analysis. Jama. 2007; 298 : 2654-64.

40. Zhang J, Yu KF. What's the relative risk? A method of correcting the odds ratio in cohort studies of common outcomes. Jama. 1998; 280: 1690-1.

41. Higgins JP, Thompson SG, Deeks JJ, Altman DG. Measuring inconsistency in meta-analyses. BMJ (Clinical research ed). 2003; 327: 557-60.

42. Begg CB, Mazumdar M. Operating characteristics of a rank correlation test for publication bias. Biometrics. 1994; 50: 1088-101.

43. Egger M, Davey Smith G, Schneider M, Minder C. Bias in meta-analysis detected by a simple, graphical test. BMJ (Clinical research ed). 1997; 315: 629-34.

44. Lange D, Heyden A, Lie ES, Brandtzaeg P, Boysen M, Clausen OPF. Lack of prognostic significance for p53-overexpression and Ki-67-immunoreactivity in oral T1-2 squamous cell carcinomas. Oncology reports. 1997; 4: 737-42.

45. Girod SC, Pfeiffer P, Ries J, Pape HD. Proliferative activity and loss of function of tumour suppressor genes as 'biomarkers' in diagnosis and prognosis of benign and preneoplastic oral lesions and oral squamous cell carcinoma. British Journal of Oral \& Maxillofacial Surgery. 1998; 36: 252-60.

46. Bova RJ, Quinn DI, Nankervis JS, Cole IE, Sheridan BF, Jensen MJ, et al. Cyclin D1 and p16(INK4A) expression predict reduced survival in carcinoma of the anterior tongue. Clinical Cancer Research. 1999; 5: 2810-9.

47. Xie X, Boysen M, Clausen OP, Bryne MA. Prognostic value of Le(y) and H antigens in oral tongue carcinomas. The Laryngoscope. 1999; 109: 1474-80.

48. Szelachowska J, Dziegiel P, Jelen-Krzeszewska J, Jelen M, Matkowski R, Pomiecko A, et al. Mcm-2 protein expression predicts prognosis better than $\mathrm{Ki}-67$ antigen in oral cavity squamocellular carcinoma. Anticancer research. 2006; 26: 2473-8.

49. Myoung $\mathrm{H}$, Kim MJ, Lee JH, Ok YJ, Paeng JY, Yun PY Correlation of proliferative markers (Ki-67 and PCNA) with survival and lymph node metastasis in oral squamous cell carcinoma: a clinical and histopathological analysis of 113 patients. International journal of oral and maxillofacial surgery. 2006; 35: 1005-10.

50. Kim SJ, Shin HJ, Jung KY, Baek SK, Shin BK, Choi J, et al. Prognostic value of carbonic anhydrase IX and Ki-67 expression in squamous cell carcinoma of the tongue. Japanese journal of clinical oncology. 2007; 37: 812-9.

51. Sakata KI, Someya M, Nagakura H, Nakata K, Oouchi A, Takagi M, et al. Brachytherapy for oral tongue cancer: An analysis of treatment results with various biological markers. Japanese journal of clinical oncology. 2008; 38: $402-7$.

52. Wang Z, Zhang B, Jiang L, Zeng X, Chen $Y$, Feng XD, et al. RACK1, an excellent predictor for poor clinical outcome in oral squamous carcinoma, similar to Ki67. European Journal of Cancer. 2009; 45: 490-6.

53. Shah NG, Trivedi TI, Tankshali RA, Goswami JV, Jetly DH, Shukla SN, et al. Prognostic significance of molecular markers in oral squamous cell carcinoma: a multivariate analysis. Head and Neck-Journal for the Sciences and Specialties of the Head and Neck. 2009; 31: 1544-56.

54. Lee JI, Jin BH, Kim MA, Yoon HJ, Hong SP, Hong SD. Prognostic significance of CXCR-4 expression in oral squamous cell carcinoma. Oral Surgery Oral Medicine Oral Pathology Oral Radiology and Endodontology. 2009; 107: $678-84$.

55. Seoane J, Pita-Fernandez S, Gomez I, Vazquez I, Lopez-Cedrun JL, De Agustin $\mathrm{D}$, et al. Proliferative activity and diagnostic delay in oral cancer. Head and Neck-Journal for the Sciences and Specialties of the Head and Neck. 2010; 32: 1377-84

56. Watanabe S, Watanabe R, Oton-Leite AF, Alencar Rde C, Oliveira JC, Leles $\mathrm{CR}$, et al. Analysis of cell proliferation and pattern of invasion in oral squamous cell carcinoma. Journal of oral science. 2010; 52: 417-24.

57. Freudlsperger C, Rohleder SE, Reinert S, Hoffmann J. Predictive value of high Ki-67 expression in stage i oral squamous cell carcinoma specimens after primary surgery. Head and Neck-Journal for the Sciences and Specialties of the Head and Neck. 2011; 33: 668-72.

58. Bitu CC, Destro MF, Carrera M, da Silva SD, Graner E, Kowalski LP, et al. HOXA1 is overexpressed in oral squamous cell carcinomas and its expression is correlated with poor prognosis. BMC cancer. 2012; 12: 146.

59. Wei ZC, Wang YL, Li ZW, Yuan CP, Zhang W, Wang DM, et al. Overexpression of Hippo pathway effector TAZ in tongue squamous cell carcinoma: correlation with clinicopathological features and patients' prognosis. Journal of Oral Pathology \& Medicine. 2013; 42: 747-54.

60. Avirovic M, Matusan-Ilijas K, Damante G, Fabrro D, Cerovic R, Juretic M, et al. Osteopontin expression is an independent factor for poor survival in oral squamous cell carcinoma: a computer-assisted analysis on TMA sections. Journal of Oral Pathology \& Medicine. 2013; 42: 620-6.
61. Gontarz M, Wyszynska-Pawelec G, Zapala J, Czopek J, Lazar A, Tomaszewska R. Proliferative index activity in oral squamous cell carcinoma: indication for postoperative radiotherapy? International journal of oral and maxillofacial surgery. 2014; 43: 1189-94.

62. Toyoda M, Kaira K, Ohshima Y, Ishioka NS, Shino M, Sakakura K, et al. Prognostic significance of amino-acid transporter expression (LAT1, ASCT2, and $x C T$ ) in surgically resected tongue cancer. British journal of cancer. 2014; 110: 2506-13

63. Couture C, Raybaud-Diogene H, Tetu B, Bairati I, Murry D, Allard J, et al. p53 and $\mathrm{Ki}-67$ as markers of radioresistance in head and neck carcinoma. Cancer. 2002; 94: 713-22.

64. Fonatsch C, Duchrow M, Rieder H, Schluter C, Gerdes J. Assignment of the human Ki-67 gene (MK167) to 10q25-qter. Genomics. 1991; 11: 476-7.

65. Schluter C, Duchrow M, Wohlenberg C, Becker MH, Key G, Flad HD, et al. The cell proliferation-associated antigen of antibody Ki-67: a very large, ubiquitous nuclear protein with numerous repeated elements, representing a new kind of cell cycle-maintaining proteins. The Journal of cell biology. 1993; 123: $513-22$

66. Urruticoechea A, Smith IE, Dowsett M. Proliferation marker Ki-67 in early breast cancer. Journal of clinical oncology : official journal of the American Society of Clinical Oncology. 2005; 23: 7212-20.

67. Scholzen T, Gerdes J. The Ki-67 protein: from the known and the unknown. Journal of cellular physiology. 2000; 182: 311-22.

68. de Azambuja E, Cardoso F, de Castro G, Jr., Colozza M, Mano MS, Durbecq V, et al. Ki-67 as prognostic marker in early breast cancer: a meta-analysis of published studies involving 12,155 patients. British journal of cancer. 2007; 96: 1504-13.

69. Martin B, Paesmans M, Mascaux C, Berghmans T, Lothaire P, Meert AP, et al. Ki-67 expression and patients survival in lung cancer: systematic review of the literature with meta-analysis. British journal of cancer. 2004; 91: 2018-25.

70. Petrelli F, Viale G, Cabiddu M, Barni S. Prognostic value of different cut-off levels of Ki-67 in breast cancer: a systematic review and meta-analysis of 64,196 patients. Breast cancer research and treatment. 2015; 153: 477-91.

71. Zhao L, Yu N, Guo T, Hou Y, Zeng Z, Yang X, et al. Tissue biomarkers for prognosis of prostate cancer: a systematic review and meta-analysis. Cancer epidemiology, biomarkers \& prevention : a publication of the American Association for Cancer Research, cosponsored by the American Society of Preventive Oncology. 2014; 23: 1047-54.

72. Gonzalez-Moles MA, Caballero R, Rodriguez-Archilla A, Ruiz-Avila I, Bravo I. Prognosis value of the expression of Ki-67 for squamous cell carcinoma of the oral cavity. Acta stomatologica Belgica. 1996; 93: 159-65.

73. Gontarz M, Wyszynska-Pawelec G, Zapala J, Czopek J, Lazar A, Tomaszewska R. Immunohistochemical predictors in squamous cell carcinoma of the tongue and floor of the mouth. Head \& neck. 2015. 